\title{
Predicting child abuse: signs of bonding failure in the maternity hospital
}

\author{
MARGARET A LYNCH, JACQUELINE ROBERTS
}

British Medical fournal, 1977, 1, 624-626

\section{Summary}

Fifty children referred to the Park Hospital because of actual or threatened abuse were compared with 50 controls born at the same maternity hospital. Five factors were significantly more common in the abused group than among their controls: (a) mother aged under 20 at birth of first child, $(b)$ evidence of emotional disturbance, (c) referral of family to hospital social worker, (d) baby's admission to special care baby unit, $(e)$ recorded concern over the mother's ability to care for child. Thirtyfive of the abused group had two or more of these factors compared with only five of the control group.

As these data were collected from information recorded routinely at the maternity hospital, it is possible to identify most abusing families when the child is born. Such identification must lead to a comprehensive assessment of each case followed by constructive preventive action.

\section{Introduction}

The necessary aim of perinatal medicine is the safe delivery of a live baby to a healthy mother. Recently, a new concern has developed that the baby should also be an accepted and loved member of the family.

The term "bonding failure" describes the failure to develop normal parent-child love. When this happens a child is at risk of abuse. If signs of bonding failure are recognised in the maternity hospital action can be taken to prevent abuse. We have examined factors that can differentiate children who are likely to be abused from a control group of children born at the same maternity hospital.

\section{Patients and methods}

Seventy per cent of the babies born to women living in the area served by Oxfordshire Area Health Authority are delivered at the John Radcliffe Maternity Hospital. Fifty of the children who were referred to Park Hospital for abuse and neglect had been born at this hospital (between July 1972 and June 1975).

Human Development Research Unit, Park Hospital for Children, Headington, Oxford OX3 7LQ

At the time of referral the 50 children belonged to four categories of child abuse, which we have defined elsewhere. ${ }^{1}$ Twenty-three were actually abused, three were probably abused, six were neglected, and 18 considered "at risk." In all cases the referee was sufficiently concerned about the family to request the specialist assessment and treatment offered at this hospital. ${ }^{2}$ Most (27) referrals came from paediatricians in Oxfordshire, but 20 came from doctors, social workers, and health visitors in the community, some being joint referrals. Three cases were referred directly from the maternity hospital.

Control group-to obtain a control group representative of the maternity hospital population we took the next live child born after each index child in the same hospital. We therefore controlled for place and time of birth. Intensive inquiries were made to discover whether any of the 50 control children had ever been abused, neglected, or considered "at risk." Questionnaires were sent to family doctors and inquiries were made at social services, paediatric, and accident and emergency departments. In only one case did a family doctor report concern about a child's safety. No child's name appeared on any "at risk" register. Nor had the question of abuse been raised on any hospital referral.

Information on the children was collected from the maternity hospital records. All available obstetric, paediatric, nursing, and social work notes were consulted. We obtained background information on social class, family size, mother's age, and obstetric, medical, psychiatric, and social history. Detailed information on the index pregnancy and neonatal period was obtained. Any details of contact with the hospital social worker were obtained from social work records. Special attention was given to any general observations recorded by any member of staff concerning parents and child during their contact with the hospital. Thus all our data were obtained from information recorded before abuse occurred.

\section{Results}

Social class-There were more families in social classes IV and V and more unemployed fathers and unsupported mothers in the abused group (table I).

Mother's age-Table II shows the ages of mothers in the two groups at the delivery of the index child and at the delivery of their first child. There was a statistically significant difference between the two groups in the proportion of women who had had their first baby when they were under 20 years.

Parity-Table III shows the mother's parity in both groups. There had been one stillbirth in each group. Four previous children from the families in the abusing group had died compared with two from the control group. Six previous children from the families with a history

TABLE I-Social class or status of families

\begin{tabular}{|c|c|c|c|c|c|c|c|}
\hline Social class: & $\begin{array}{l}\text { I and } \\
\text { II }\end{array}$ & III & IV & V & $\begin{array}{c}\text { In armed } \\
\text { Forces }\end{array}$ & Unemployed & $\begin{array}{c}\text { Un- } \\
\text { supported } \\
\text { mothers }\end{array}$ \\
\hline $\begin{array}{l}\text { Abused group } \\
\text { Control group }\end{array}$ & $\begin{array}{r}1 \\
12\end{array}$ & $\begin{array}{r}6 \\
17\end{array}$ & $\begin{array}{l}15 \\
12\end{array}$ & $\begin{array}{l}9 \\
1\end{array}$ & $\begin{array}{l}7 \\
5\end{array}$ & $\begin{array}{l}5 \\
1\end{array}$ & $\begin{array}{l}7 \\
2\end{array}$ \\
\hline
\end{tabular}


TABLE II-Mother's age at birth of first baby and time of delivery of index child

\begin{tabular}{l|c|c|c|c}
\hline \multicolumn{1}{r}{ Age (years): } & $<20$ & & 20 & Total \\
\cline { 1 - 3 } & \multicolumn{1}{c}{ Birth of first baby } & & \\
Abused group & $25^{*}$ & 25 & 50 \\
Control group & $8^{*}$ & 42 & 50 \\
& Birth of index child & & \\
Abused group & $10^{\dagger}$ & 40 & 50 \\
Control group & $4 \dagger$ & 46 & 50 \\
\hline
\end{tabular}

${ }^{*} \chi^{2}=13 \cdot 12 ; \mathrm{P}<0.001$.

$+\chi^{2}=3.02 ;$ not significant.

TABLE III-Parity

\begin{tabular}{r|r|r|r|r|r|r|r}
\hline \multicolumn{1}{r|}{ Para: } & 1 & 2 & 3 & 4 & 5 & 6 & 7 \\
\hline $\begin{array}{l}\text { Abused group } \\
\text { Control group }\end{array}$ & 19 & 17 & 8 & 2 & 2 & 1 & 1 \\
\hline
\end{tabular}

of abuse had been adopted or placed with long-term foster parents. There was no such case reported in the control group. There were twin pregnancies in the abusing group, resulting in four live births (four index cases). There was one twin pregnancy in the control group resulting in one live child and one macerated stillbirth (excluded from the study). There was no statistically significant difference between the number of primiparous women in the two groups. This seems to indicate that previous experience of motherhood does not necessarily protect against bonding failure.

Sex of child-Of the abused children 21 were girls and 29 boys. Twenty-three of the controls were girls and 27 boys.

Complications in pregnancy-The mothers of 27 abused children had had to be admitted to hospital for complications of pregnancy compared with 20 mothers of control children. The difference was not statistically significant.

Recorded emotional disturbance-We counted the entries in the section on "psychiatric illness" in the antenatal notes. Many comments were not descriptions of formal psychiatric illness, but all were evidence of notable emotional disturbance. This information depends on the mother's reports, the interviewer, and the referring family doctor, so its reliability varies. Nevertheless, "psychiatric illness" had been attributed to mothers of 23 abused children compared with seven mothers of controls $\left(\chi^{2}=12.2 ; P<0.001\right)$. Examples of emotional disturbance were: depression, with or without treatment; "breakdowns"; "suicide attempts"; drug addiction; contact with child psychiatrists; being a runaway; and educational subnormality.

Referral to hospital social worker-There is a social work department in the maternity hospital, which included two full-time social workers at the time of the study. Patients may be referred by any member of staff or community workers or they may refer themselves. The parents of 29 abused children had been referred to the hospital social worker during either the pregnancy or the neonatal period compared with only three of the control parents $\left(\chi^{2}=31.06 ; P<0.001\right)$.

Complications in labour or delivery-These included transfer from a general practitioner unit in labour; operative deliveries, excluding those recorded as easy lift-out forceps; 3rd stage complications (haemorrhages, retained placenta); breech and twin deliveries; shoulder dystocia; and labours resulting in delivery of infant under 37 weeks' gestation. The mothers of 22 abused children had had abnormal labour or delivery, or both. Eight had had a caesarian section. Seventeen of the control group mothers had had complications, including four who had undergone caesarian section.

\section{INFANTS}

Special care nursery admission-Only very preterm and ill babies are admitted to the special care baby unit, which has intensive care facilities but a caring and friendly atmosphere. Families are encouraged to visit, and the nurses are beginning to share more of the babies' care with the parents. ${ }^{3}$ Twenty-one $(42 \%)$ of the abused babies had been admitted to the special care nursery, compared with only five $(10 \%)$ of the control babies $\left(\chi^{2}=13.2 ; P<0.001\right)$. The overall rate of admission in the hospital during the period studied was $13 \%$. Seventeen of these 21 abused babies had spent a week or more in the special care nursery. As indicated by these admission rates, there were far more babies who had been born preterm and "small-for-dates" (birth weight below 10th centile for gestational age $)^{4}$ in the abused group. Eleven abused babies had been born before 37 weeks' gestation compared with only one of the controls. Thirteen of the singletons in the abused group had been "small-for-dates" compared with only five of the singletons in the control group.

Recorded concern over mothering-When analysing the maternity hospital records we noticed that the hospital staff had occasionally expressed direct concern about the mother's ability to cope with her child's physical or emotional needs-“cannot stand her baby's cry," "has not visited baby for more than a week," "does not know how to respond to baby's needs," were typical comments. Therefore we made a systematic search of all the maternity records in both groups for written evidence of this concern. Each of us looked at the records independently. The mothers of 22 abused babies had evoked concern, compared with only three control mothers $\left(\chi^{2}=19.24 ; \mathrm{P}<0.001\right)$.

Adverse factors in both groups-Five of the factors examined were highly significantly overrepresented in the abused group: (a) mother aged under 20 years at birth of first child; $(b)$ emotional disturbance recorded; $(c)$ referral to hospital social worker; $(d)$ baby's admission to special care unit; $(e)$ concern over mothering recorded in notes. The distribution of these adverse factors in both groups is shown in table IV. All five adverse factors are interrelated. The mother who is emotionally disturbed and who causes concern about her mothering ability is more likely to be referred to the social worker. We therefore found a striking accumulation of adverse factors in the abused group, 35 children having two or more. Only five of the control group had more than one adverse factor.

TABLE IV-Adverse factors

\begin{tabular}{|c|c|c|c|c|c|c|}
\hline No of factors: & 0 & 1 & 2 & 3 & 4 & 5 \\
\hline $\begin{array}{l}\text { Abused group } \\
\text { Control group }\end{array}$ & $\begin{array}{r}4 \\
31\end{array}$ & $\begin{array}{l}11 \\
14\end{array}$ & 11 & $\begin{array}{r}12 \\
2\end{array}$ & $\begin{array}{l}9 \\
0\end{array}$ & $\begin{array}{l}3 \\
0\end{array}$ \\
\hline
\end{tabular}

\section{Discussion}

The aim of our research was to help busy maternity hospital staff in identifying families in need of extra help in loving and caring for their baby. The findings we have described were available in the maternity notes before abuse ever occurred. Although we were aware of which children were subsequently abused, we were restricted to indisputable facts-for example, admission to the special care nursery-and explicit written evidence.

No one isolated factor can be used to predict abuse. Abusing parents have wide-ranging, diffuse, and interrelated problems. ${ }^{5}$ In this study the accumulation of often interconnected medical and social problems differentiated the abusing parents from their controls.

The factors that emerge as highly overrepresented in the abusing group highlight characteristics often observed in abusing families. The early age at which these parents reproduce has been reported by many. ${ }^{2}$ 6-8 Both "recorded emotional disturbance" and "referral to the social worker" are signs of the interrelated emotional and practical problems that have beset these parents, often since childhood. ${ }^{9}$ We have shown that parents at Park Hospital can be differentiated from most of those referred to maternity hospital social workers because of the diffuse nature of their problems. ${ }^{1}$ They have a series of long-term and interlocking difficulties, from which there seems to be no escape. ${ }^{10}$ Although adverse social conditions are found, it is the severity of the relationship problems that is most striking.

If a baby has to be admitted to the special care nursery because of extreme prematurity or illness the normal bonding process with his parents is jeopardised and the risk of abuse increased. ${ }^{811}$ Mothers who find difficulty in caring for their infants often give warning signals to the staff of the maternity hospital.12-15 Their "concern over mothering" may actually be recorded by the staff but does not necessarily lead to appropriate action.

Recognising the early signs of bonding failure is only the beginning. Preventing subsequent child-rearing difficulties 
should be the aim of all those responsible for the care of the child and his family. As the mothers of $29(58 \%)$ abused children were referred to the maternity hospital social worker, it is clear that social work help alone cannot prevent battering. There seems to be a need for co-ordinating all disciplines, both in hospital and in the community, to provide preventive help for the parents. Treatment projects in different settings have already shown that prevention is possible. ${ }^{16-18}$ The use of data such as ours merely to compile "at-risk" registers would result only in despondency and frustration.

The research was funded by Action Research for the Crippled Child. JR is seconded by. Oxfordshire social services department. Secretarial help was given by Miss Alison van Dedem Edwards, who is funded by the Oxford Regional Health Authority locally organised research scheme. We thank all the staff at the John Radcliffe Maternity Hospital whose notes made this study possible, the family doctors for their kind interest and co-operation, and Dr C Ounsted and Dr J Lindsay for their advice and encouragement.

\section{References}

${ }^{1}$ Lynch, M A, et al, Developmental Medicine and Child Neurology, 1976, $18,759$.

${ }^{2}$ Lynch, M A, and Ounsted, C, in Child Abuse and Neglect. The Family and the Community, ed R E Helfer and C H Kempe, ch XI. Cambridge, Mass, Ballinger, 1976.
${ }^{3}$ Howat, P, Paper on predicting and preventing child abuse given at Tunbridge Wells Study Group, October 1976.

${ }^{4}$ Davis, P A, et al, Clinics in Developmental Medicine, No 44-45. Medical Care of New-born Babies. London, Spastics International Medical Publications and Heinemann, 1972.

${ }^{5}$ Lynch, M A, Journal of Maternal and Child Health, 1976, 1, 1.

${ }^{6}$ Smith, S M, et al, British Medical fournal, 1976, 4, 388.

${ }^{7}$ National Society for the Prevention of Cruelty to Children, Case Work and Development Department, Registers of Suspected Non-accidental Injury London, NSPCC, 1975.

${ }^{8}$ Lynch, M A, Lancet, 1975, 2, 317.

${ }^{9}$ Baldwin, J A, and Oliver, J E, British fournal of Preventive and Social Medicine, 1972, 29, 4.

10 Ounsted, C, and Lynch, M A, in Child Abuse and Neglect. The Family and the Community, ed R E Helfer and C H Kempe, ch VI. Cambridge, Mass, Ballinger, 1976.

${ }^{11}$ Klaus, M, and Kennell, J, fournal of Pediatric Clinics of North America, $1970,17,1016$

${ }^{12}$ Kempe, C H, Archives of Disease in Childhood, 1971, 46, 28.

${ }^{13} \mathrm{Gray}, \mathrm{J}$, et al, in Child Abuse and Neglect. The Family and the Community, ed R E Helfer and C H Kempe, ch XIX. Cambridge, Mass, Ballinger, 1976.

${ }^{14}$ Fanaroff, A A, Kennell, J H, and Klaus, M H, Pediatrics, 1972, 49, 287.

15 Helfer, R E, and Kempe, C H, (editors), Helping the Battered Child and his Family, ch 5. Philadelphia and Toronto, Lippincott, 1972.

${ }^{16}$ Ounsted, C, Oppenheimer, R, and Lindsay, J, Developmental Medicine and Child Neurology, 1974, 16, 4.

${ }^{17}$ Beswick, K, Lynch, M A, and Roberts, J, British Medical fournal, 1976, 2, 800 .

${ }^{18}$ Kempe, $\mathrm{C} \mathrm{H}$, and Helfer, R E, (editors), Helping the Battered Child and his Family, ch 3. Philadelphia and Toronto, Lippincott, 1972.

(Accepted 29 November 1976)

\title{
Survey of safety and health care in British medical laboratories
}

\author{
J M HARRINGTON, H S SHANNON
}

British Medical fournal, 1977, 1, 626-628

establishing regulations for codes of safe practice rather than relying merely on recommendations as at present.

\section{Summary}

A retrospective postal survey of 24000 medical laboratory workers in England, Wales, and Scotland showed highly variable standards of safety and health care. Preemployment health screening was offered to two-thirds of employees, the physicians being the least likely to be examined $\left(15^{\circ}{ }^{\circ}\right)$. Scottish laboratories provided better safety control than English and Welsh laboratories, while Public Health Service Laboratories had a better record than National Health Service establishments. Mouth pipetting is still practised in $65^{\circ}{ }^{\circ}$, of English and Welsh laboratories, and the use of protective clothing is rarely compulsory. The servicing of safety cabinets is often inadequate. Known and suspected carcinogens are still apparently used in a few laboratories $\left(2-10^{\circ}\right)$.

In view of the wide variation in standards among laboratories, urgent consideration should be given to

TUC Centenary Institute of Occupational Health, London School of Hygiene and Tropical Medicine, London WC1E 7HT

J M HARRINGTON, MD, MRCP, lecturer in occupational medicine (present address: Environmental Hazards Activity, Cancer and Birth Defects Division, Bureau of Epidemiology, Centre for Disease Control, Atlanta, Georgia 30333, USA)

H S SHANNON, MSC, FSS, statistician

\section{Introduction}

Medical laboratory workers are exposed to a wide variety of occupational hazards. These include specific risks, such as laboratory-acquired infections, ${ }^{2}$ as well as the more general risks of laboratory practice such as fires, explosions, gassings, and physical injury. ${ }^{3}{ }^{4}$ Few epidemiological studies of laboratory populations have been undertaken. In 1957 Reid $^{5}$ noted an increased risk among British medical laboratory workers of acquiring tuberculosis of between two and nine times the national rates. Laboratory workers are also exposed to many chemicals. Bladder tumours occur more often in medical and paramedical workers, ${ }^{6}$ and the death rate among professional chemists in the USA from lymphomata and carcinoma of the pancreas is higher.?

Our report is part of a three-year survey of the health of British medical laboratory workers. Tuberculosis incidence rates are two to five times greater than in the general population, ${ }^{8}$ though a mortality study showed no clear-cut picture of increased cancer mortality, except possibly for lymphomata. ${ }^{9}$ Suicide rates suggested that access to chemicals might influence the high mortality rate, particularly with regard to the method of suicide.

In view of these real and potential occupational hazards, we tried to assess the standard of health care available to laboratory workers in the National Health Service (NHS), Public Health 